\section{Relato de experiência: "grandes poetas brasileiros", um programa multilinguagem de incentivo à leitura em escolas e bibliotecas municipais do Rio de Janeiro}

An experience with "major Brazilian poets," a multilanguage project for encouraging poetry reading and writing for students in public schools and libraries of Rio de Janeiro

João Pedro Fagerlande, Doutorando em Literatura Brasileira, UFRJ/CAPES, joaofager@gmail.com

\section{Resumo}

Apresentamos aqui a experiência com o projeto "Grandes Poetas Brasileiros", um programa de incentivo à leitura realizado pelo grupo Poesia Viral em escolas municipais (2014) e em bibliotecas municipais (2015), destinado a estudantes da rede pública e com patrocínio da Secretaria Municipal de Cultura do Rio de Janeiro.

Palavras chave: Ensino; Leitura; Poesia.

\section{Abstract}

This paper presents the experience with "Major Brazilian Poets", a project in public libraries and schools in Rio de Janeiro in 2014 and 2015, created by the Poesia Viral group and sponsored by the Secretary of Culture of Rio de Janeiro. The project is designed for students in the public school system, and its goal is to encourage poetry reading and writing.

Key words: Poetry; Reading; Teaching literature. 


\section{Introdução}

O projeto "Grandes Poetas Brasileiros" é um programa de incentivo à leitura que busca apresentar a poesia a estudantes da rede municipal do Rio de Janeiro numa abordagem lúdica e interativa, sem perder de vista a relação com o texto escrito. Contemplado duas vezes no Programa de Fomento à Cultura Carioca, da Secretaria Municipal de Cultura, o programa foi realizado em seis escolas no ano de 2014 e em 2015 ocorre em dez bibliotecas públicas da cidade.

No programa são utilizados recursos teatrais, projeções multimídia e zines literários, configurando a ação como uma prática multilinguagem.

\section{Problema}

A maioria dos jovens sai da escola sem nunca ter lido um livro inteiro de poesia, como nos lembra o professor Helder Pinheiro (2007), professor da UFPA, que há mais de vinte anos pesquisa o ensino de poesia nas escolas. Ele considera que a abordagem dos professores é um dos principais fatores que contribuem para este índice e aponta em seu livro "Poesia na sala de aula" diversas possibilidades para se trabalhar com o gênero literário, dentre eles a teatralização dos textos - uma das estratégias que utilizamos no projeto para aproximar a poesia dos jovens.

Porém, como enfatiza o professor e consultor na área de leitura Élie Bajard (2014), a simples oralização dos textos não contribui para a construção do hábito da leitura. Além desse primeiro momento, é necessário chegar ao texto escrito, encaminhando o jovem para a leitura silenciosa e individual.

O programa Grandes Poetas Brasileiros busca atender esses dois propósitos, além de oferecer ao jovem a possibilidade de se expressar nas oficinas de criação, realizando, portanto, um percurso poético que passa tanto pela recepção quanto pela expressão literária. 


\section{V SILID IV SIMAR

\section{$\angle O$ CULTURA \\ 5 PRESENTE! RIO \\ Prefeitura da cidade do Rio de Janeiro

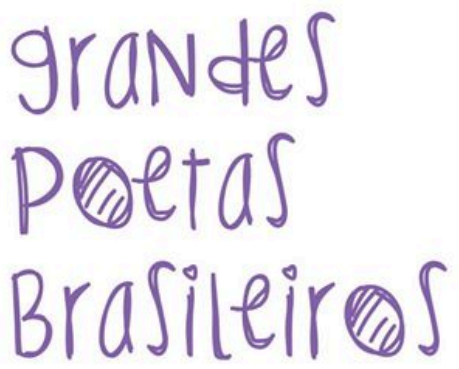

PROGRAMA DE INCENTIVO À LEITURA EM BIBLIOTECAS MUNICIPAIS DO RIO DE JANEIRO para estudantes da rede pública de agosto a novembro de 2015
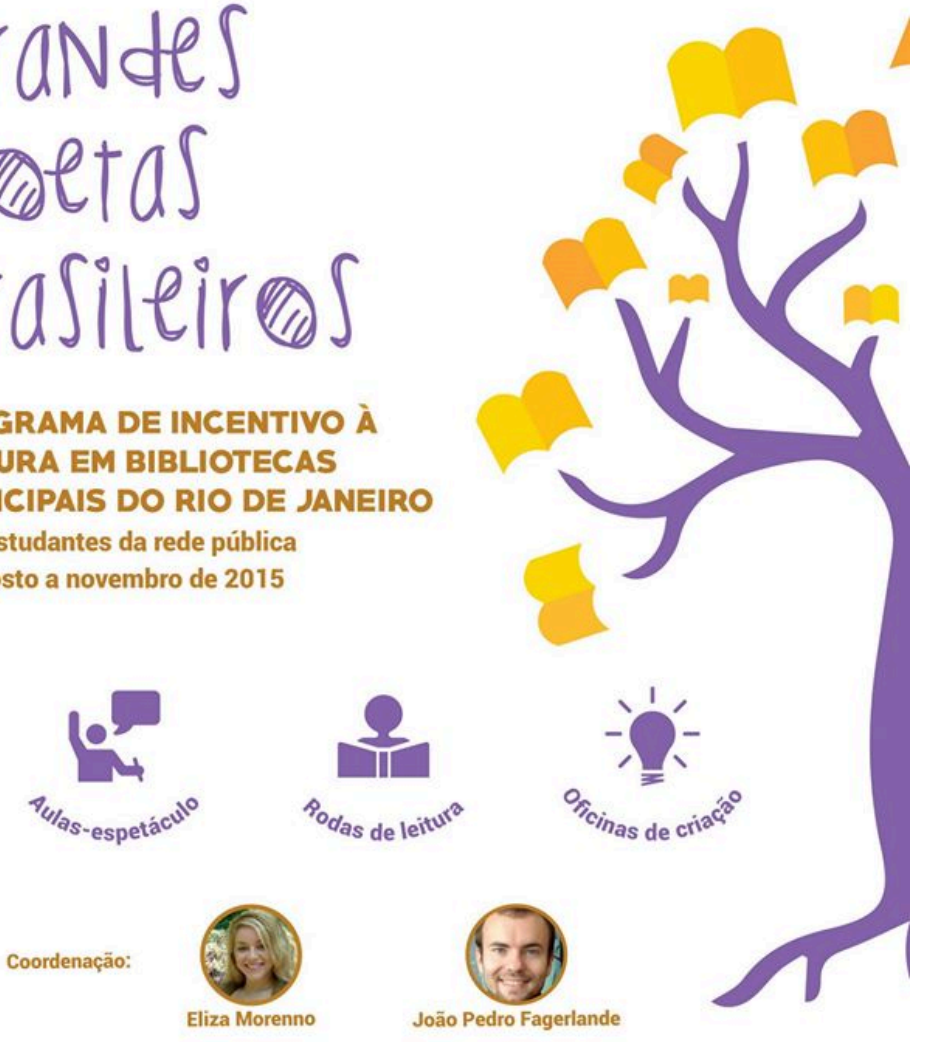

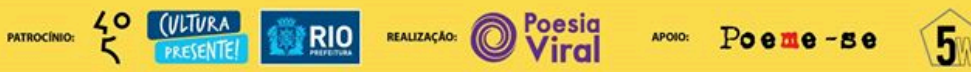

Imagem 1: arte de divulgação do projeto em 2015.

\section{Propósito}

O presente estudo busca apresentar a metodologia e os fundamentos do projeto "Grandes Poetas Brasileiros", no sentido de estabelecer uma reflexão teórica a partir de uma prática que já ocorre na cidade do Rio de Janeiro. Acreditamos que esta reflexão, além de embasar melhor as ações do projeto, serve também para dar visibilidade ao programa e estimular a criação de novos métodos para o ensino de poesia.

O programa é composto de três etapas, que serão melhor apresentadas no item "Métodos": aulas espetáculo, rodas de leitura e oficinas de criação. Os poetas selecionados são Carlos Drummond de Andrade, Cecília Meireles, Ferreira Gullar e Vinícius de Morais. 


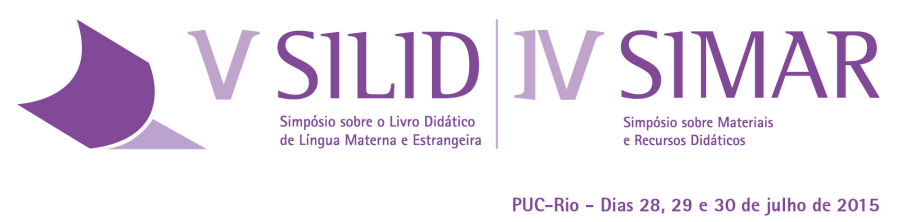

\section{Abordagens teóricas}

Em seu livro Literatura em perigo, Tzedan Todorov discute um problema que vem ocorrendo no ensino de literatura nas escolas, que é o das teorias estarem se sobrepondo aos textos em si. Como sintetiza o tradutor do livro, Caio Meira, no prefácio:

O perigo mencionado por Todorov não está, portanto, na escassez de bons poetas ou ficcionistas, no esgotamento da produção ou da criação poética, mas na forma como a literatura tem sido oferecida aos jovens, desde a escola primária até a faculdade: o perigo está no fato de que, por uma estranha inversão, o estudante não entra em contato com a literatura mediante a leitura dos textos literários propriamente ditos, mas com alguma forma de crítica, de teoria ou de história literária. (...) Para esse jovem, literatura passa a ser então muito mais uma matéria escolar a ser aprendida em sua periodização do que um agente de conhecimento sobre o mundo, os homens, as paixões, enfim, sobre sua vida íntima e pública. (p.10)

Nossa experiência escolar nos faz lembrar como as aulas de literatura eram organizadas em critérios históricos, através dos estilos de época. Tal modo de organização acaba por privilegiar muitas vezes textos de difícil acesso aos jovens como, por exemplo, cantigas trovadorescas medievais, escritas em português arcaico, criando um imaginário de a literatura ser algo muito distante da realidade presente. Não que o conhecimento dessas formas literárias seja algo a ser descartado, mas talvez não sejam elas o melhor atrativo para despertar nos jovens a vontade de ler, de travar contato com livros.

Daniel Pennac, em seu famoso livro Como um romance, considera ser mais importante alimentar o entusiasmo da leitura em lugar de pôr à prova sua competência (p.55). Muitas vezes a escola cai nesse lugar de instrumentalização da literatura, isto é, de avaliar se o aluno de fato compreendeu o texto, em detrimento de estimular o prazer literário. Além disso, frequentemente poemas são utilizados em sala de aula com o único propósito de ilustrar lições sintáticas, colaborando nesse ideal de instrumentalização.

O grande problema nessas questões é que a literatura deixa de ser apresentada como uma forma de prazer, fator que, atrelada a outras questões de ordem sociológica, pode estar afastando os jovens dos livros. "Grandes Poetas Brasileiros" procura apresentar a poesia sem cobrar avaliações, sem se basear em critérios históricos, mas com a finalidade única de estimular um encontro prazeroso com textos de alguns de nossos maiores autores, oferecendo aos jovens um outro modo de lidar com a literatura. 


\section{SILID IV SIMAR}

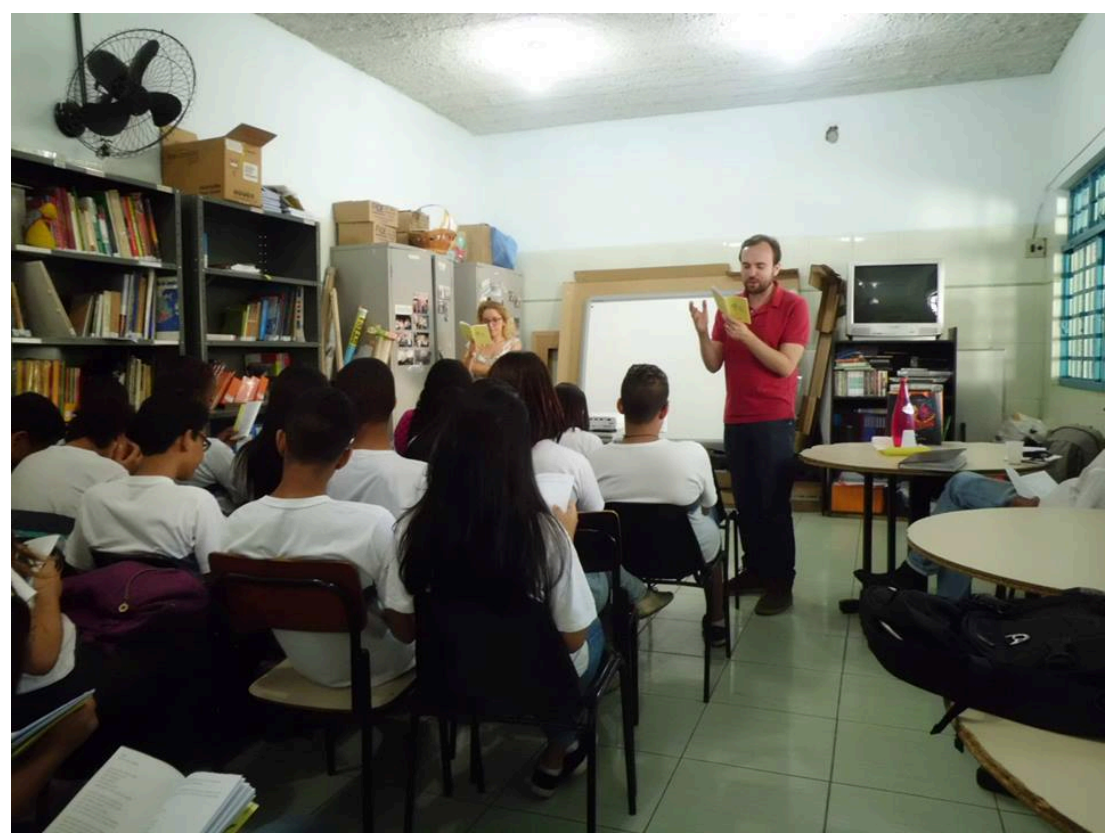

Imagem 2: roda de leitura para turma da Escola Municipal Cuba, da Ilha do Governador.

\section{Métodos}

"Grandes Poetas Brasileiros" tem três núcleos de atividade, realizadas na seguinte ordem: aulas espetáculo, rodas de leitura e oficinas de escrita. Os textos trabalhados no programa são de Carlos Drummond de Andrade, Cecília Meireles, Ferreira Gullar e Vinícius de Morais. A escolha dos textos utilizados tem como critérios a qualidade literária e a comunicabilidade, tendo em vista se tratar de um programa de incentivo à leitura.

As aulas espetáculo são uma etapa introdutória, que apresentam a vida e a obra dos poetas por meio de dramatização de poemas, projeções multimídia e comentários biográficos sobre os autores. Buscando a empatia dos alunos, os mediadores trabalham a partir do conceito de performance estabelecido por Paul Zumthor (2007), que considera a prática como um modo vivo de comunicação poética. Como os dois mediadores também são atores, a performance tem um papel de destaque nesta etapa, que tem como objetivo estabelecer uma relação lúdica e afetiva dos alunos com poesia, através dos recursos teatrais e multimídia. Com a turma já engajada e disponível para a leitura, entramos na etapa seguinte.

Nas rodas de leitura os alunos têm contato direto com os textos na forma escrita, fator que consideramos fundamental para o incentivo à leitura de livros de poesia. São distribuídos zines literários com uma antologia dos autores selecionados, que são lidos e comentados conjuntamente. Como ressalta Helder Pinheiro (2007), a maioria dos alunos sai da escola sem nunca ter lido um livro inteiro de poesia, lacuna esta que procuramos preencher, na medida do possível, ao distribuir os zines/antologias. Porém nem todos os textos são lidos presencialmente 
com os alunos, para que eles possam terminar a leitura de maneira individual, ocupando aquilo que Élie Bajard (2014) chama de "zona de autonomia", que o autor considera necessário para o incentivo à leitura.

A última etapa do programa é a oficina de criação, em que os alunos podem expressar seus sentimentos/pensamentos de maneira livre, a partir dos conhecimentos aprendidos nas etapas anteriores. Ao final dessa etapa, realizamos um pequeno sarau para os alunos voluntariamente lerem seus textos para a turma. A duração total do programa é de $2 \mathrm{~h}$ para cada grupo de até 40 estudantes.

Em 2014 foram realizadas 60h de atividades em seis escolas municipais, nos bairros Botafogo, Copacabana, Gávea, Grajaú e Vila Isabel. Em 2015 são 100h de atividades em dez bibliotecas municipais (de Botafogo, Campo Grande, Centro, Ilha do Governador, Irajá, Jacarepaguá, Santa Cruz e Tijuca), atendendo turmas de escolas públicas em sessões agendadas.

Todas as atividades são pensadas, articuladas e executadas pela Poesia Viral, formada por Eliza Morenno e João Pedro Fagerlande.

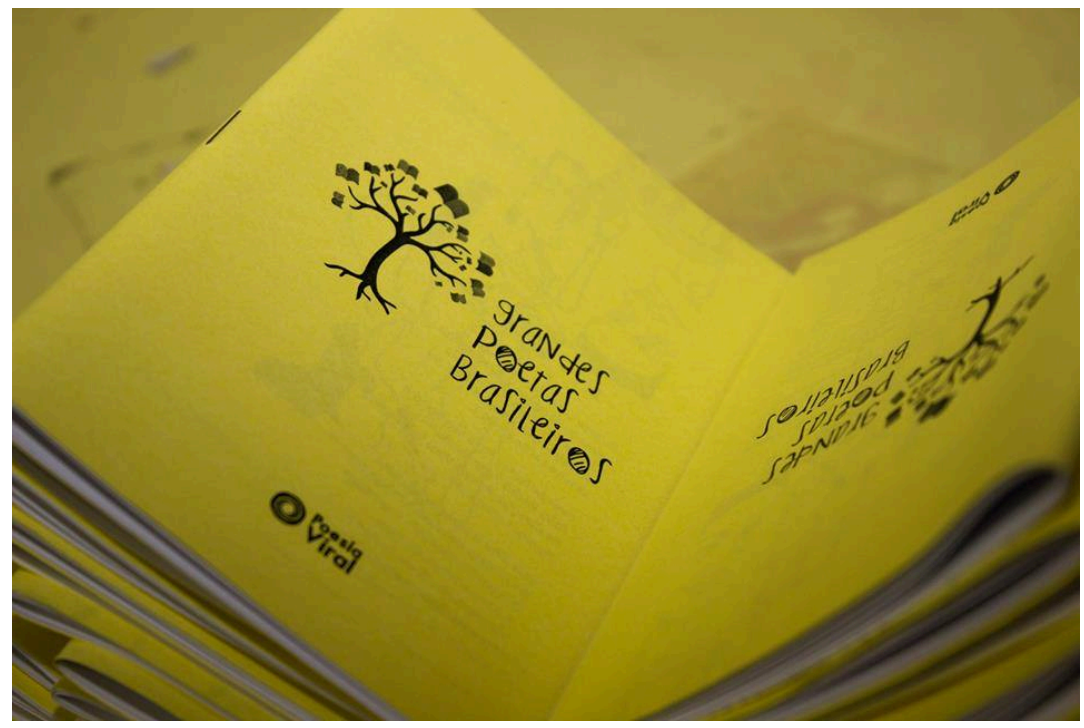

Imagem 3: zines literários com antologia dos autores selecionados são distribuídos para os alunos.

\section{Considerações}

"Grandes Poetas Brasileiros" está sendo realizado pelo segundo ano em 2015, com algumas modificações em relação a 2014. O espaço de realização das atividades deixou de ser as escolas municipais, passando para as bibliotecas municipais. $\mathrm{O}$ fato de agora os alunos irem para as bibliotecas é um estímulo para pegarem livros emprestados e frequentarem este espaço público.

Em 2014 nós distribuímos apostilas com os poemas, mas para 2015 consideramos mais interessante distribuir zines com a antologia poética. A parceria 
com a editora $5 \mathrm{~W}$ possibilitou a criação de um material de qualidade, elaborado por um diagramador profissional.

Em 2015 estamos testando uma plataforma digital para mantermos os alunos conectados com o projeto no Facebook. Na plataforma, estudantes de diferentes escolas e bairros da cidade podem interagir a partir da poesia, postando seus próprios textos, comentando/curtindo os dos outros, ou compartilhando uma informação, vídeo etc.

Consideramos que o projeto, como um mecanismo vivo, ainda pode ser modificado no sentido de melhorar nossos processos e abordagens. $O$ fato de estarmos levando a iniciativa para discussão no meio acadêmico vem justamente nesse sentido, de trocarmos com colegas e professores nossas experiências, buscando melhores resultados no incentivo à leitura de poesia.

\section{Referências Bibliográficas}

BAJARD, Élie. Da escuta de textos à leitura. São Paulo: Cortez, 2014.

PENNAC, Daniel. Como um romance. Trad. Leny Werneck. Rio de Janeiro: Rocco, 1993.

PINHEIRO, Hélder. Poesia na sala de aula. Campina Grande: Bagagem, 2007.

TODOROV, Tzvetan. Literatura em perigo. Trad. Caio Meira. Rio de Janeiro: DIFEL, 2009.

ZUMTHOR, Paul. Performance, recepção e leitura. Trad. Jerusa Pires e Suely Fenerich. São Paulo: Cosac Naify, 2007. 